\title{
EL TRABAJO DE LA MEMORIA EN CENTROAMÉRICA: CINCO PROPUESTAS HEURÍSTICAS EN TORNO A LAS GUERRAS EN EL SALVADOR, GUATEMALA Y NICARAGUA
}

\author{
Ralph Sprenkels*
}

Resumen: Este artículo presenta una exploración comparativa del trabajo de la memoria en torno a las guerras de la segunda mitad del siglo XX en tres países centroamericanos: El Salvador, Guatemala y Nicaragua. Identifica cinco diferentes propuestas heurísticas para explicar las guerras (incluyendo sus principales causas y secuelas), que se utilizan, en mayor o menor medida, en cada país: el olvido impuesto, la guerra fraternicida, la revolución, el anticomunismo, y el desengaño. Vinculados con sectores políticos e históricos

Fecha de recepción: 01/06/2017 - Fecha de aceptación: 01/07/2017

* Antropólogo e historiador de origen holandés. Estudió historia y español en la Universidad de Guadalajara (México). Máster en Estudios Latinoamericanos de la Universidad de Amsterdam y un Doctor en Ciencias Sociales de la Universidad Utrecht. Enfoca sus investigaciones en temáticas relacionadas con las secuelas políticas de conflictos armados, incluyendo política partidaria de posguerra, derechos humanos y memoria histórica. Co-fundador, junto con Jon Cortina SJ, de la Asociación Pro-Búsqueda de Niñas y Niños Desaparecidos en El Salvador, organización donde laboró de 1994 al 2002. Co-fundador también, en 2009, de la Unidad de Investigaciones sobre la Guerra Civil Salvadoreña (UIGCS), que funciona en la Universidad de El Salvador, bajo la responsabilidad de Jorge Juárez. Ha publicado varios libros sobre la guerra civil y niñez desaparecida en El Salvador, así como un volumen sobre el movimiento de derechos humanos en El Salvador titulado The Price of Peace. The Human Rights Movement in Postwar El Salvador (Cuadernos de CEDLA, 2005). Asimismo, ha publicado varios artículos y capítulos sobre la dinámica política de la gestión de la memoria en El Salvador. Su libro más reciente saldrá próximamente en University of Notre Dame Press con el título After Insurgency in El Salvador. How the Revolutionary Movement Assimilated Electoral Politics. Correo electrónico: r_sprenkels@yahoo.es 
determinados, estas propuestas heurísticas cuentan con niveles de incidencia diferenciados en cada país. Su estudio permite visualizar la arena política del trabajo de la memoria en cada país, a la vez que permite analizar similitudes y diferencias entre los tres países. Enfocando el trabajo de la memoria como proceso político contencioso y relativamente fragmentado, el presente artículo contribuye a dimensionar los impactos del trabajo de la memoria en torno a las pasadas guerras en las sociedades centroamericanas en cuestión.

Palabras clave: memoria colectiva; guerra civil; heurística; revolución; anticomunismo; historia; El Salvador; Guatemala; Nicaragua.

\begin{abstract}
This article presents a comparative exploration of contemporary memory work related to the wars of the second half of the twentieth century in three Central American countries: El Salvador, Guatemala and Nicaragua. It identifies five different heuristic proposals forwarded to explain the essential features of these wars (including their main causes and consequences). I refer to these heuristic proposals respectively as "imposed oblivion," "war among brothers," "revolution," "anti-communism," and "disillusionment." Linked to specific political and historical sectors, these heuristic proposals have different levels of traction in each country. Their study allows to visualize the political arena of memory work in each country, while also providing input for an analysis of similarities and differences in war-related memory work between the three countries. Focusing on memory work as a contentious and relatively fragmented political process, the present article contributes to weighing the contemporary impact of war-related memory work in the Central American societies in question.
\end{abstract}

Keywords: Collective Memory; Civil War; Heuristic; Revolutions; Anti-communism; History; El Salvador; Guatemala; Nicaragua.

History is not the past. It is the present. We carry our history with us. We are our history.

James Baldwin 
El trabajo de la memoria en Centroamérica: cinco propuestas heurísticas en torno a las guerras en El Salvador, Guatemala y Nicaragua.

\section{Introducción ${ }^{1}$}

¿En qué y en quiénes pensamos las y los académicos cuando hablamos de las guerras de la segunda mitad del siglo XX en Centroamérica? El trabajo de las y los historiadores presenta invariablemente inclusiones y exclusiones. Atribuye valor a ciertos individuos, colectivos y acontecimientos, e ignora, anula o cuestiona el valor de otros. Tal como lo sugieren Mónica Contreras y otros, para muchos académicos latinoamericanos el trabajo de la memoria tiene una doble vertiente: una de análisis académico y otra de activismo. ${ }^{2}$ Poner en el punto de la mira a algunas figuras y acciones, y no a otras, lleva implícita no solamente una teleología interpretativa, sino también una lección política. Hay muchísimo en juego. De nuestra interpretación del pasado depende en gran parte la agenda de futuro que podemos o debemos empujar.

Para las y los que estudiamos la gestión de la memoria en Centroamérica no resulta nada fácil abstraernos de esta dinámica. Muchos de nosotras o nosotros, especialmente los que nacimos en los años 50 y 60 , nos formamos en ámbitos impregnados o dominados por proyectos revolucionarios. Tal como lo expresa de manera sublime Roberto Bolaño en su obra literaria, muchos y muchas de nosotros cargamos - y seguimos cargando- de una o de otra manera con el duelo del fracaso de estos proyectos. Los legados de la revolución (fallida) son diversos ${ }^{3} \mathrm{y}$ siguen siendo particularmente fuertes para las generaciones que vivieron las guerras. ${ }^{4}$ Persiste la indignación y el dolor

1 El presente trabajo se basa en la participación del autor en el coloquio Las múltiples huellas del recuerdo. Las memorias de la guerra en Centroamérica en perspectiva comparada, organizado por la Universidad de Costa Rica, que tuvo lugar en San José, Costa Rica, del 24 al 26 de agosto de 2016. Agradezco a Patrica Alvarenga y los demás organizadores del coloquio por facilitar este encuentro. Agradezco de manera particular a Patricia Alvarenga, Carlos Gregorio López Bernal, Mauricio Menjívar, Jorge Juárez, Werner Mackenbach y Lorena Carrillo por el diálogo entablado y sus muchos comentarios enriquecedores a mi ponencia. Agradezco asimismo a los dos evaluadores anónimos y a Saskia van Drunen por su lectura y valiosos comentarios.

$2 \mathrm{Al}$ respecto, vea los planteamientos de MemoriAL - Red Interdisciplinaria de Estudios sobre Memoria en América Latina, accessible en URL: https://lamemory.wordpress.com/.

3 El análisis más completo de los legados socio-políticos de los procesos revolucionarios centroamericanos lo ofrece Edelberto Torres Rivas, Revoluciones sin cambios revolucionarios: ensayos sobre la crisis en Centroamérica. (Guatemala, Guatemala: F\&G Editores, 2011).

4 Para análisis de los reacomodos de posguerra en distintas comunidades y sectores vinculados al proyecto revolucionarios en El Salvador, Guatemala, y Nicaragua, veáse Michael Allison, "The Transition from Armed Opposition to Electoral Opposition in Central America", Latin American Politics and Society (EE. UU.) 48, 4 (2006): 137-162, URL: http://www.jstor. org/stable/4490495; Silvia Posocco, Secrecy and Insurgency: Socialities and Knowledge Practices in Guatemala (Tuscaloosa: University of Alabama Press, 2014); Daniel Chávez, 
de la represión. Persiste la imagen del enemigo. Persiste también la noción de que la labor académica debe servir no solamente para conocer el mundo, sino también para hacer la revolución, o por lo menos para transformar el mundo.

Mi aproximación de la temática de la memoria se enfoca de manera particular en lo que Jansen llama 'el trabajo de la memoria', que se refiere al lanzamiento de la memoria en espacios públicos por medio de discursos, actividades ritualizadas y productos tales como panfletos, monumentos, anuncios, libros, murales, entrevistas, documentales, etc. ${ }^{5}$ Aunque el trabajo de la memoria puede expresarse de manera particularmente potente y visible en algunos momentos específicos altamente coreografiados, como la apertura de una exposición o la inauguración de un monumento, para sus gestores la memoria consiste a menudo también en un trabajo diario, casi cotidiano, de construir, documentar y defender ciertas versiones del pasado. ${ }^{6}$ El trabajo de la memoria gira entonces en torno a la construcción y certificación de marcos de interpretación del pasado que nos pavimentan el camino del futuro. Fuertemente impregnados de aspectos emotivos y afectivos, estos marcos funcionan como herramientas heurísticas, ya que inducen a las personas a filtrar sus percepciones del mundo y adjudicar significados a su entorno a partir del uso selectivo de información y conocimiento. ${ }^{7}$

Nicaragua and the Politics of Utopia: Development and Culture in the Modern State (Nashville, Tennessee, EE. UU.: Vanderbilt University Press, 2015); Kristina Pirker, La redefinición de lo posible: militancia y movilización social en El Salvador (1970-2004) (Tesis de doctorado, Universidad Nacional Autónoma de México, 2008); Ralph Sprenkels, After Insurgency in El Salvador. How the Revolutionary Movement Assimilated Electoral Politics (Notre Dame, Indiana, EE. UU.: University of Notre Dame Press, en prensa); Rubén Zamora, La izquierda partidaria salvadoreña: Entre la identidad y el poder (San Salvador, El Salvador: FLACSO, 2003).

5 Veáse Robert Jansen, "Resurrection and Appropriation: Reputational Trajectories, Memory Work, and the Political Use of Historical Figures", American Journal of Sociology (EE. UU.) 112, 4 (Enero 2007): 953-1007, DOI: https://doi.org/10.1086/508789. Un inventario bastante completo para el caso de El Salvador, lo ofrece Georgina Hernández Rivas, Cartografía de la memoria: actores, lugares y prácticas en El Salvador de posguerra (1992-2015) (Tesis Doctoral, Universidad Autónoma de Madrid, 2015).

6 Tal como lo explica Susan Sontag: "Lo que se denomina memoria colectiva no es un recuerdo sino una declaración: que ésto es importante, que ésta es la historia de lo ocurrido, con las imágenes que ... compendian ideas comunes de significación y desencadenan reflexiones y sentimientos predecibles". En: Susan Sontag, Ante el dolor de los demás (México, D.F.: Santillana, 2002), 100.

7 Véase Jim Kuypers, Rhetorical Criticism: Perspectives in Action (Lanham, EE. UU.: Lexington Books, 2009). 
El trabajo de la memoria en Centroamérica: cinco propuestas heurísticas en torno a las guerras en El Salvador, Guatemala y Nicaragua.

El propósito central de este artículo consiste en generar una reflexión sobre los patrones heurísticos que dominan el trabajo de la memoria en torno a las pasadas guerras en Centroamérica. En algunos de mis trabajos previos enfaticé el fenómeno de la manipulación política partidaria de la memoria de la guerra en El Salvador. La Alianza Republicana Nacionalista (ARENA) y el Frente Farabundo Martí para la Liberación Nacional (FMLN), los dos partidos políticos que han dominado la arena política de la posguerra en este país, se enfocan principalmente en la gestión de lo que llamo una 'memoria militante' ${ }^{8}$ Estos dos partidos, ambos 'hijos de la guerra' ${ }^{9}$ e históricos enemigos, promueven de manera enfática su propia interpretación del conflicto armado, que descalifica al rival y enaltece a los propios. ${ }^{10}$ Carlos Gregorio López Bernal ofrece una tipología más amplia, haciendo distinción entre cuatro formatos de memoria de guerra que se encuentran expresadas comúnmente en el FMLN y su entorno: la memoria martirial, la heroica, la festiva y la oficial. ${ }^{11}$ Cada formato enfatiza elementos distintos y ofrece interpretaciones marcadamente divergentes del conflicto armado, más no necesariamente disonantes. Ampliando aún más la reflexión, el historiador estadounidense Erik Ching demuestra en un sobresaliente trabajo reciente que es posible establecer un claro nexo entre interpretaciones concretas y vividas de la guerra con determinadas comunidades políticas en El Salvador. ${ }^{12}$ Ching identifica cuatro grupos de protagonistas salvadoreños, y cada uno lanza al espacio público su

8 Veáse Ralph Sprenkels, "La memoria militante. Historia y política en la posguerra salvadoreña”, en: Conflicto, memoria y pasados traumáticos: El Salvador contemporáneo, (ed.) Eduardo Rey Tristán y Pilar Cagiao Vila (Santiago de Compostela, España: Universidad de Santiago de Compostela, 2011); Ralph Sprenkels, "La guerra como controversia: una reflexión sobre las secuelas políticas del informe de la Comisión de la Verdad para El Salvador", Identidades. Revista de Ciencias Sociales y Humanidades (El Salvador) año 2, 4 (2012): 68-89, disponible en URL: https://es.scribd.com/document/134157541/Rev-Identidades-N-4; Ralph Sprenkels, "Roberto d'Aubuisson Versus Schafik Handal. Militancy, Memory Work and Human Rights", European Review of Latin American and Caribbean Studies (Holanda) 91 (2011): 15-30, DOI: http://doi.org/10.18352/erlacs.9240.

9 Jeroen de Zeeuw, "Sons of war: parties and party systems in post-war El Salvador and Cambodia", Democratization, 17, n. 6 (2010): 1176-1201, DOI: http://dx.doi.org/10.1080/13510 347.2010.520549.

10 Veáse también Carlos Gregorio López Bernal.

11 Carlos Gregorio López Bernal en "El FMLN y las memorias de la guerra civil salvadoreña", publicado en esta misma entrega de la revista.

12 Erik Ching, Stories of Civil War in El Salvador. A Batte Over Memory (Chapel Hill, EE. UU.: University of North Carolina Press, 2016). 
propia narrativa interpretativa sobre el pasado conflicto armado: elites civiles, oficiales militares, comandantes guerrilleros y participantes de base. ${ }^{13}$

El denominador común de los esfuerzos académicos mencionados en el párrafo anterior es la identificación de lo que podría concebirse como proyectos contrastantes de gestión de la memoria. Se trata de divergentes propuestas heurísticas que se vinculan estrechamente con determinadas comunidades políticas, que tuvieron papeles distintos y/o antagónicos en la pasada guerra. En el caso de El Salvador, esta dimensión política de la gestión de la memoria de la guerra se hace particularmente patente, posiblemente por la fuerza del 'boom de la memoria' ${ }^{14}$ que se vive en este país, aunado a la preponderancia política contemporánea de los protagonistas de la guerra. Sin embargo, Guatemala y Nicaragua, los otros dos países del istmo centroamericano que sufrieron conflictos armados recientes, también cuentan con diversas propuestas heurísticas de memoria de guerra más o menos consistentes, vinculadas a determinadas comunidades políticas en estos países. Los paralelismos y divergencias en las propuestas heurísticas de mayor calado público en El Salvador, Guatemala y Nicaragua dan insumos para una reflexión comparativa, que busco desarrollar de manera preliminar en este artículo.

Más importante a mi juicio es la constatación de que la identificación y el análisis de propuestas heurísticas de memoria ofrece una ventana interesante y novedosa a las dinámicas políticas contemporáneas de las sociedades centroamericanas y a las raíces históricas de estas dinámicas. ${ }^{15}$ Estas propuestas y su resonancia evidencian que los legados de las pasadas guerras cuentan con una gran incidencia en el istmo. Su estudio comparativo ayuda a comprender las encrucijadas políticas que enfrenta el istmo en la actualidad y constituyen un complemento necesario y urgente para la comprensión los alcances y limitaciones de la democratización centroamericana. ${ }^{16}$

\section{$13 \mathrm{Ibid}, 244-248$.}

14 Veáse Jorge Juárez, "Memoria e historia reciente en El Salvador. La necesidad de nuevos mitos en el presente salvadoreño" en: Conflicto, memoria y pasados traumáticos: El Salvador contemporáneo, (ed.) Eduardo Rey Tristán y Pilar Cagiao Vila (Santiago de Comospetla, España: Universidad de Santiago de Compostela, 2011).

15 Para un mayor desarrollo de este argumento, veáse Ching, Stories of Civil War ..., 14.

16 Para estudios recientes sobre la democratización posguerra en Centroamérica y sus limitaciones, veáse Fabrice Lehoucq, The Politics of Modern Central America. Civil War, Democratization, and Underdevelopment (Cambridge: Cambridge University Press, 2012); Jennifer Burrell y Ellen Moodie (ed.), Central America in the New Millennium: Living Transition and Reimagining Democracy (New York: Berghahn Books, 2012); Benedicte Bull, "Governance in the Aftermath of NeoLiberalism: Aid, Elites and State Capacity in Central America", Forum of Development Studies, 43, n. 1 (2016), 89-111, DOI: http://dx.doi.org/1 
El presente artículo se estructura de la siguiente manera. A continuación presento una breve elaboración teórica que se centra en la dinámica política de la gestión de proyectos de memoria. Después exploro, con base en estos puntos de partida conceptuales, algunas de las principales tendencias y patrones que se pueden identificar en el trabajo de la memoria en torno a las recientes guerras centroamericanas. Identifico tentativamente cinco propuestas heurísticas de especial relevancia e impacto público. Si bien estas propuestas heurísticas tienden a asociarse estrechamente con determinados actores históricos, a la vez funcionan como posibles repertorios a los que actores políticos pueden recurrir para hacer efectiva la interpretación de la guerra, en la labor política que estos actores desarrollan en el contexto de la posguerra.

\section{Algunas consideraciones teóricas sobre la memoria como herramienta política}

El trabajo de la memoria se vincula con individuos y redes sociales y políticas concretas. Eviatar Zerubavel argumenta en este sentido que la gestión de la memoria se estructura y ordena en torno a lo que llama comunidades mnemónicas. ${ }^{17}$ Iwona Irwin utiliza el término "comunidades de memoria" para destacar cómo miembros de una sociedad pueden dividirse en diferentes grupos sociales que comparten una interpretación del pasado que se distingue de o incluso contradice la de los otros grupos. ${ }^{18}$ Estas comunidades de la memoria o comunidades mnemónicas consisten entonces en grupos de personas que comparten importantes puntos de referencia y se cohesionan por compartir marcos de interpretación del pasado, similar a lo que Fligstein y McAdam, basándose en la sociología de Bourdieu, llaman campos de acción social estratégica. ${ }^{19}$ Actores inmersos en un determinado campo de acción social trabajan para dotarlo de sentido y orden, por ejemplo, estableciendo prestigio y jerarquías internas, y generando contraste, distancia o cercanía con otros campos sociales. ${ }^{20}$ Propongo entender entonces una comunidad mnemónica

$0.1080 / 08039410.2015 .1134647$.

17 Véase, Eviatar Zerubavel, Time Maps: Collective Memory and the Social Shape of the Past (Chicago: University of Chicago Press, 2003).

18 Véase, Iwona Irwin-Zarecka, Frames of Remembrances: The Dynamics of Collective Memory (New Brunswick, Canadá: Transaction Publishers, 1994).

19 Véase, Niel Fligstein y Doug McAdam, A Theory of Fields (Oxford: Oxford University Press, 2012).

20 Véase, Pierre Bourdieu, Distinction. A Social Critique of the Judgement of Taste (Londres, Ingalterra: Routledge, 1984). 
como un tipo de campo social cuya apuesta central reside en la producción de una determinada propuesta heurística del pasado. Ya que la heurística del pasado constituye el principal fundamento de la representación política, la trascendencia política de las comunidades mnemónicas es enorme. ${ }^{21} \mathrm{O}$ sea, todo credo político se construye sobre las supuestas lecciones que nos ofrece el pasado. Partiendo de estas ideas, se hace patente que la gestión de la memoria juega un papel clave en la construcción de las diversas comunidades políticas que en la actualidad disputan ascendencia en el istmo centroamericano.

Dicho eso, no es fácil ordenar las sociedades centroamericanas en una variedad de comunidades mnemónicas. Parte de la dificultad reside en el hecho de que estas comunidades no pueden ni deben concebirse como invariables ni homogéneas. Tal como lo señala Ching, las comunidades mnemónicas no necesariamente se autoidentifican como tal, y a menudo cuentan con una dinámica interna compleja y llena de aristas y divisiones entre facciones. ${ }^{22}$ Este fenómeno se relaciona con el hecho de que el trabajo de la memoria no solamente sirve para posicionar a una comunidad de memoria frente a otras comunidades de memoria. Como ya vimos con la anterior referencia a Bourdieu, el trabajo de la memoria constituye a la vez una herramienta de poder -capital cultural y simbólico- que ayuda posicionar a un individuo o subgrupo dentro del grupo social en el cual se mueve.

El trabajo de la memoria busca entonces una doble resonancia: una resonancia pública, fortaleciendo la posición de una determinada versión de la historia vis-à-vis otras versiones que compiten por la resonancia pública, y una resonancia que puede llamarse 'interna', que busca contribuir a la gestión de las jerarquías dentro de su misma comunidad mnemónica. En esto último cuenta, por ejemplo, a quién se atribuye poder representar la comunidad mnemónica con su voz y ejemplo. De esta manera, en el campo de acción del trabajo de la memoria no solamente compiten diferentes comunidades mnemónicas, sino también diferentes participantes en una misma comunidad mnemónica entre sí. Esto impregna a la práctica socio-política del trabajo de la memoria de una fuerte dinámica discursiva que por momentos puede, incluso, llegar a confundirse con una cacofonía. Además, ya que el trabajo

21 Véase, Frank Ankersmit, Political Representation (Stanford, EE. UU.: Stanford University Press, 2002).

22 Erik Ching, Stories of Civil War... 
El trabajo de la memoria en Centroamérica: cinco propuestas heurísticas en torno a las guerras en El Salvador, Guatemala y Nicaragua.

de la memoria no se caracteriza tanto por una repetición estática sino por la producción analógica, también el contenido del trabajo de la memoria puede resultar esquivo, ya que está sujeto a ciertos márgenes de reinterpretación que le imprime al trabajo de la memoria un dinamismo permanente. ${ }^{23}$

Lo que une a una comunidad mnemónica es el enarbolar de versiones afines de la historia, versiones que a grandes rasgos comparten la misma propuesta heurística. La heurística, en esencia, no es más que una herramienta de simplificación cognitiva del mundo que nos rodea. ${ }^{24}$ Se trata de estructuras de conocimiento que pueden utilizarse para simplificar las tareas de interpretar, juzgar, y tomar decisiones. ${ }^{25}$ Es su capacidad heurística la que convierte a las narrativas públicas en herramientas efectivas para la política y la acción social. ${ }^{26}$ Reducidas a su esencia heurística, las narrativas públicas presentan una variación bastante limitada. ${ }^{27}$ En el marco de este artículo, una propuesta heurística de la memoria se refiere entonces a una narrativa simbólica simplificada de la historia de las pasadas guerras, que determinada comunidad utiliza públicamente para procesar la historia de una manera contemporáneamente provechosa a los ojos de dicha comunidad.

La gestión de propuestas heurísticas sobre el significado de los conflictos armados comienza incluso antes de la materialización de las guerras en Centroamérica. Acompaña a los procesos bélicos antes, durante y después. La gestión de la memoria de acontecimientos y figuras asociadas a la guerra, asimismo, ya tiene lugar antes de la finalización del conflicto. Sin embargo, para los fines del presente artículo nos enfocaremos en la gestión de la memoria en el período posbélico que se abre con la firma de la paz en los países en cuestión. Un

23 Gregor Feindt, Félix Krawatzek, Daniela Mehler, Friedemann Pestel y Rieke Timcev, "Entangled Memory: Toward a Third Wave in Memory Studies", History and Theory, 53, n. 1 (febrero 2014): 24-44, DOI: http://dx.doi.org/10.1111/hith.10693.

24 Daniel Kahneman y Shane Frederick, "Representativeness revisited: Attribute substitution in intuitive judgment", en: Heuristics and Biases: The Psychology of Intuitive Judgment, (ed.) Thomas Gilovich, Dale Griffin y Daniel Kahneman (New York: Cambridge University Press, 2002).

25 Stefan Rompf, Trust and Rationality: An Integrative Framework for Trust Research (Wiesbaden, Alemania: Springer, 2014), 181.

26 Robert Benford y David Snow, "Framing Processes and Social Movements: An Overview and Assessment", Annual Review of Sociology (EE. UU.) 26 (2000): 611-639, DOI: https:// doi.org/10.1146/annurev.soc.26.1.611.

27 Véase, Andrei Cimpian, "The Inherence Heuristic: Generating Everyday Explanations", en: Emerging Trends in the Social and Behavioral Sciences, (ed.) Robert Scott y Stephan Kosslyn (Nueva Jersey, EE. UU.: John Wiley \& Sons, 2015). 
enfoque principal está en la cristalización de diferentes propuestas heurísticas de la memoria que han acompañado la transición de posguerra en Centroamérica.

\section{La heurística del olvido impuesto}

Amparada en la famosa advertencia de que "los pueblos que olvidan su historia están condenados a repetirla", ${ }^{28}$ existe una importante tradición latinoamericana que conceptualiza el trabajo por la memoria en contraposición a lo que percibe como el olvido impuesto desde sectores hegemónicos de la sociedad. ${ }^{29}$ Surgido con fuerza a partir de los setenta y ochenta en el cono sur latinoamericano, constituye una reacción cívica a los intentos de los diversos regímenes sucesores de las dictaduras represivas de negar o minimizar los abusos históricos. Al igual que en el resto de América Latina, la heurística de la lucha contra el olvido impuesto encontró en Centroamérica a sus mayores proponentes en las organizaciones de derechos humanos y sectores de la iglesia. ${ }^{30}$ El surgimiento de una comunidad activista y profesional de derechos humanos a nivel internacional se tradujo, asimismo, en significativos apoyos para la lucha contra el olvido y la negación en Centroamérica. ${ }^{31}$ Estos antecedentes, aunados al trabajo realizado por organizaciones de derechos humanos en Centroamérica, llevó a que el tema del esclarecimiento histórico de los abusos cometidos en la guerra fuera un punto importante en la agenda de las negociaciones de paz en El Salvador y Guatemala, auspiciadas en ambos casos por la Organización de las Naciones Unidas. ${ }^{32}$

28 Dicha frase se atribuye comunment al filósofo hispano-estadounidense George Santayana. Veáse Enrique Moradiellos, Las caras de Clio. Una introducción a la historia (Madrid, España: Siglo XXI Editores, 2009), 304.

29 Veáse Manuel Antonio Garretón, "Human Rights in Processes of Democratization", Journal of Latin American Studies 26, n. 1 (febrero 1994): 221-234, DOI: https://doi.org/10.1017/ S0022216X00018903; Priscilla Hayner, Unspeakable Truths: Confronting State Terror and Atrocity (New York: Routledge, 2000); Elizabeth Jelin, Los Trabajos de la Memoria (Madrid, España: Siglo XXI Editores, 2001).

30 Veáse Frank Afflitto y Paul Jesilow, The Quiet Revolutionaries: Seeking Justice in Guatemala (Austin, Texas, EE. UU.: University of Texas Press, 2007); Ralph Sprenkels, The Price of Peace. The Human Rights Movement in Postwar El Salvador (Amsterdam, Holanda: Cuadernos de CEDLA, 2005); Gloria Guzmán y Irantzu Mendía, Mujeres con memoria: activistas del movimiento de derechos humanos en El Salvador (Bilbao, España: Hegoa, 2013).

31 Katryn Sikkink, The Justice Cascade: How Human Rights Prosecutions Are Changing World Politics (New York, EE. UU.: W.W. Norton, 2011).

32 Sobre las negociaciones de paz y su agenda, veáse Salvador Samayoa, El Salvador. La reforma pactada (San Salvador, El Salvador: UCA Editores, 2002); Susanne Jonas, De centauros y palomas: el proceso de paz guatemalteco (Guatemala, Guatemala: FLACSO, 2000). 
El trabajo de la memoria en Centroamérica: cinco propuestas heurísticas en torno a las guerras en El Salvador, Guatemala y Nicaragua.

A partir de la labor que las respectivas comisiones esclarecedoras internacionales realizaron en El Salvador y en Guatemala, ambas se convirtieron en referente obligado para el análisis del trabajo de la memoria sobre los conflictos armados en estos dos países. Su importancia, sin embargo, tiene una doble cara. Si bien las comisiones esclarecedoras abonaron al conocimiento de lo que ocurrió en las guerras en estos dos países, y a la difusión de este conocimiento, las respuestas divergentes y antagónicas a los informes presentados también mostraron la resistencia de varios sectores a aceptar sus hallazgos como la nueva versión oficial de los hechos. A los ojos de las organizaciones de derechos humanos, los informes de verdad fueron seguidos de un olvido impuesto a servicio de los perpetradores. ${ }^{33}$ Este olvido, a su vez, fue tenazmente combatido desde sectores comprometidos con la lucha en contra de la impunidad.

En el caso de El Salvador, el informe de la Comisión de la Verdad, presentado en 1993, causó en su momento un gran revuelo nacional..$^{34}$ El Ministro de Defensa, en conferencia de prensa y respaldado por todo su Estado Mayor conjunto, calificó el informe titulado "De la locura a la esperanza" de "injusto, incompleto, ilegal, antiético, parcial y atrevido". ${ }^{35}$ También hubo críticas del lado de la antigua guerrilla del FMLN, y principalmente de parte de la dirigencia del Ejército Revolucionario del Pueblo (ERP), una de las cinco organizaciones guerrilleras integrantes del FMLN, que reclamó que la comisión se hubiera enfocado principalmente en los abusos del ERP, dejando de lado a las otras organizaciones guerrilleras. Según los comandantes del ERP dichas organizaciones guerrilleras habrían manipulado a la comisión para perjudicarlos a ellos. ${ }^{36} \mathrm{El}$ informe de la Comisión de la Verdad fue seguido por la adopción en la Asamblea Legislativa de la Ley de Amnistía General para la Consolidación de la Paz, que efectivamente impidió un procesamiento jurídico de los hechos, algo que contribuyó a la continuada polémica sobre las verdaderas

33 Helen Beatriz Mack Chang, "La reconciliación en Guatemala: un proceso ausente", en: Verdad, justicia y reparación: desafios para la democracia y la convivencia social, (ed.) Gilda Pacheco Oreamuno, Lorena Acevedo Narea y Guido Galli (Instituto Internacional para la Democracia y la Asistencia Electoral / Instituto Interamericano de Derechos Humanos, 2005); Guzman y Mendía, Mujeres con memoria ...; Sprenkels, "La guerra como Controversia...".

34 El informe puede accesarse a través del sitio web de Procuraduría para la Defensa de los Derechos Humanos de El Salvador, en URL: http://www.pddh.gob.sv/memo/verdad.

35 José María Rico, Justicia penal y transición democrática en América Latina (Ciudad de México y Madrid: Siglo XXI Editores, 1997), 57.

36 Sprenkels, "La guerra como controversia...", 76. 
responsabilidades de los implicados. ${ }^{37}$

En el caso de Guatemala, buscando aumentar lo que en aquel entonces ya se interpretaba como el limitado impacto de la comisión en El Salvador, la Iglesia Católica, con la ayuda de organizaciones internacionales, emprendió un esfuerzo titánico de documentación detallada de los abusos cometidos en el contexto del conflicto armado. El proyecto, llamado 'Recuperación de la Memoria Histórica' (REMHI), resultó en lo que puede caracterizarse como una enciclopedia de atrocidades, que llevó el título 'Guatemala: nunca más' ${ }^{38}$ El obispo Juan Gerardi presentó el informe REMHI en la catedral de la Ciudad de Guatemala el día 24 de abril de 1998. Fue asesinado en la casa parroquial donde residía dos días después. ${ }^{39}$

Con estos antecedentes dolorosos y preocupantes, el personal de Naciones Unidas, a través de la Comisión de Esclarecimiento Histórico (CEH) para Guatemala, se esforzó por producir un informe aún más extenso y exhaustivo que "Nunca más", que llevó el título 'Guatemala: memoria del silencio'. ${ }^{40}$ Amarrado por el mandato de la negociación, y contrario al caso de la Comisión de la Verdad en El Salvador, la CEH, sin embargo, no pudo incluir los nombres de los mandos responsables de las atrocidades en el informe. Al final, no obstante la impresionante y abrumadora documentación de las violaciones de los derechos humanos ofrecida por las dos comisiones, muchos sectores políticos guatemaltecos obviaron los contenidos de los informes, o los descalificaron como interpretaciones ideologizadas y foráneas de lo sucedido. ${ }^{41}$

En el contexto de la paz, las antiguas organizaciones político-militares de ambos países, que habían tenido una fuerte incidencia en las organizaciones de derechos humanos a lo largo del conflicto, se terminaron retirando parcial o completamente de la lucha por la justicia, en el caso de las violaciones a los

37 Margaret Popkin, Peace without Justice. Obstacles to Building the Rule of Law in El Salvador (University Park, EE. UU.: Pennsylvania State University Press, 2000). La Ley de Amnistía fue derogada por la Corte Suprema de Justicia de El Salvador en julio de 2016. A la fecha, no está claro aún cuáles serán las consecuencias de dicha derogación para lucha en contra de la impunidad en El Salvador.

38 El informe puede accesarse a través del URL: http://www.odhag.org.gt/html/Default.htm.

39 Francisco Goldman, The Art of Political Murder: Who Killed the Bishop? (New York, EE. UU.: Grove Press, 2007).

40 El primer tomo del informe se puede accesar a través del sitio web del Programa de Naciones Unidas para el Desarrollo (PNUD) en Guatemala, en URL: https://goo.gl/ZR9F2B.

41 Anita Isaacs, "At War with the Past? The Politics of Truth Seeking in Guatemala", The International Journal of Transitional Justice (Inglaterra) 4, n. 2 (julio 2010), 1-24, DOI: https:// doi.org/10.1093/ijtj/ijq005; Jonas, De centauros y palomas... 
El trabajo de la memoria en Centroamérica: cinco propuestas heurísticas en torno a las guerras en El Salvador, Guatemala y Nicaragua.

derechos humanos del conflicto. ${ }^{42}$ En parte, esta maniobra puede entenderse como un daño colateral de los informes de la verdad: aunque claramente el ejército y los paramilitares aparecen como los mayores violadores de los derechos humanos, tanto en El Salvador como en Guatemala, el pequeño porcentaje de casos en los que se estableció la responsabilidad de la guerrilla, sin embargo, podría convertirse en problemas jurídicos y políticos para los comandantes. El distanciamiento de los revolucionarios con la histórica bandera de los derechos humanos obedeció, asimismo, al declive de la lucha diplomática que habían sostenido los insurgentes a lo largo de los ochenta para aumentar su legitimidad y conseguir apoyos internacionales. También respondía a la necesidad de reconvertirse de fuerza insurgente en partido político y de enfocarse en la lucha electoral..$^{43}$

Los esfuerzos de las comisiones esclarecedoras, en El Salvador y en Guatemala respectivamente, no pudieron impedir entonces que desde el Estado y los partidos conservadores, y con la complicidad de parte de las élites de la antigua insurgencia, se instalara entonces como política principal de la gestión de las deudas del pasado el principio del 'borrón y cuenta nueva'. ${ }^{44}$ De forma similar a lo ocurrido en el cono sur latinoamericano, desde el poder del Estado, y con la complicidad de sectores conservadores y reaccionarios, se fueron ignorando o marginando aquellos hallazgos y versiones que amenazaron los intereses de los perpetradores. ${ }^{45} \mathrm{~A}$ las heridas del pasado había que aplicárseles el bálsamo de 'perdón y olvido'. Los informes de verdad tal vez complicaron el ejercicio, pero no truncaron la capacidad de actores políticos e institucionales de abocarse a la negación. ${ }^{46}$

42 Para la relación entre las organizaciones guerrilleras y el movimiento de derechos humanos en el caso de Guatemala, veáse David Stoll, Rigoberta Menchú and the Story of All Poor Guatemalans (Boulder, Colorado, EE. UU.: Westview Press, 1999); para la relación entre el FMLN y el movimiento de derechos humanos en el caso de El Salvador, veáse: Sprenkels, The Price of Peace...

43 Sprenkels, The Price of Peace..., 104.

44 Mack Chang, "La reconciliación en Guatemala..."; María Elena Barahona y Martha Liliana Gutiérrez Salazar, "El Salvador: The Difficult Fight Against Impunity", en: Transitional Justice in Latin America: The Uneven Road from Impunity Towards Accountability, (ed.) Elin Skaar, Jemima Garcia-Godos y Cath Collins (Londres, Inglaterra: Routledge, 2016).

45 Veánse inter alia Alexandra Barahona de Brito, Paloma Aguilar Fernández y Carmen González Enríquez, Las políticas hacia el pasado: juicios, depuraciones, perdón y olvido en las nuevas democracias (Madrid, España: Istmo, 2002); Steven Stern, Remembering Pinochet's Chile: On the Eve of London 1998 (Durham, Carolina del Norte, EE. UU.: Duke University Press, 2004).

46 Para una elaboración teórica y comparativa de políticas de olvido, veánse Stanley Cohen, States of Denial. Knowing about Atrocities and Suffering (Malden, Massachusetts, EE. UU.: 
Ante las tendencias negacionistas, varios actores sociales guatemaltecos y salvadoreños emprendieron lo que concibieron como una lucha contra el olvido, tomando la delantera en el trabajo de la memoria, y tratando de hacer desde otros espacios lo que el Estado obviaba. Lideradas por organizaciones de derechos humanos, partes de lo que se conoce como 'sociedad civil' se pusieron la tarea de desarrollar una cartografía cada vez más extensa y precisa de las atrocidades cometidas, ampliando el trabajo previo de las Comisiones de Verdad. Surgieron organizaciones especializadas en hacer reconstrucciones minuciosas, tales como el Equipo de Antropología Forense de Guatemala o el Museo de la Palabra y la Imagen en El Salvador, que lograron documentar partes importantes, pero obliteradas, de la historia del conflicto y lanzarlas al espacio público. ${ }^{47}$

Los dos esfuerzos quizás más icónicos que nacieron de este empuje para romper el olvido impuesto son el Archivo de la Policía en Guatemala y la Asociación Pro-Búsqueda en El Salvador. El primer proyecto se originó en un hallazgo fortuito en 2005. Haciendo una inspección de un almacenamiento militar de explosivos en un terreno de la capital, empleados de la Procuraduría de los Derechos Humanos de Guatemala encontraron ahí una enorme bodega llena de papeles semiabandonados. Al verificarlos, resultaron ser los archivos de la antigua Policía Nacional de Guatemala, disuelta como resultado de los Acuerdos de Paz. ${ }^{48}$ Con el apoyo de la Procuraduría, las Naciones Unidas y varias organizaciones de derechos humanos se procedió con un proyecto de salvaguardar, ordenar y digitalizar los folios. Este proyecto sigue en curso y ha generado ya más de 19 millones de folios digitalizados, un acervo impresionante que incluye información detallada sobre las víctimas y sobre el modus operandi de la Policía Nacional, tal como lo describe Kirsten Weld en su libro Cadáveres de papel..$^{49}$ Asimismo, después de varios años de pugnas políticas, el Archivo de la Policía Nacional es ahora parte del Archivo de la Nación en Guatemala, logrando un respaldo oficial, aunque siempre bastante precario. ${ }^{50}$

Polity Press y Blackwell Publishers, 2001); Michel-Rolph Trouillot, Silencing the Past: Power and the Production of History (Boston, EE. UU.: Beacon Press, 1995).

47 Hernández Rivas, Cartografia de la memoria...; Erica Henderson, Catherine Nolin y Fredy Peccerelli, "Dignifying a Bare Life and Making Place through Exhumation: Cobán CREOMPAZ Former Military Garrison, Guatemala", Journal of Latin American Geography (EE. UU.) 13, n. 2 (2014): 97-116, DOI: https://doi.org/10.1353/lag.2014.0027.

48 Kirsten Weld, Paper Cadavers: The Archives of Dictatorship in Guatemala (Durham, Carolina del Norte, EE. UU.: Duke University Press, 2014).

49 Ibid.

$50 \mathrm{Ibid}$, capítulo 8 . 
El trabajo de la memoria en Centroamérica: cinco propuestas heurísticas en torno a las guerras en El Salvador, Guatemala y Nicaragua.

Pro-Búsqueda nació en 1994 como resultado de los esfuerzos de activistas de derechos humanos, que tenían en el jesuita Jon Cortina su integrante más conocido, y de familiares de niños desaparecidos por realizar una búsqueda de su destino..$^{51}$ Como miembro del colectivo inicial que fundó Pro-Búsqueda, fui testigo del avance de este proceso. Inicialmente nos enfrentamos no solo al escepticismo de las instancias oficiales, sino también de muchos activistas, que veían improbable que aún estuvieran con vida las y los niños que nosotros buscábamos. En este tiempo manteníamos lazos estrechos con el FMLN y nos avocamos a la dirigencia para pedir ayuda. También ahí hubo escepticismo. Consideraban que nuestro trabajo revolvía demasiado el pasado y que le daba falsas expectativas a la gente..$^{52}$ Con el tiempo, cuando se logró comprobar el alcance de la problemática, con centenares de casos documentados, y cuando se lograron también los primeros reencuentros, este escepticismo desapareció hasta cierto punto. A partir de resoluciones de la Corte Interamericana incluso se llegó a formar una Comisión Nacional de Búsqueda de Niñas y Niños Desaparecidos, de carácter estatal, en el período de gobierno del Presidente Saca. ${ }^{53}$

Esta comisión, ubicada en el Ministerio de Relaciones Exteriores, seguía funcionando en 2016, aunque sin acceso de los archivos militares, un requisito necesario para seguir resolviendo más casos. ${ }^{54}$ Incluso después del acceso al poder del FMLN en 2009, no se avanzó en este acceso. En 2011, el presidente Mauricio Funes declaró ante la prensa, y con David Munguía Payés, su Ministro de Defensa, al lado, que los archivos militares que organizaciones como Pro-Búsqueda querían ver en realidad no existían, ni tenían información relevante para poder resolver los casos de violaciones..$^{55}$ Ante la

51 Para más información sobre el surgimiento y la labor de Pro-Búsqueda, veánse Ralph Sprenkels (ed), El día más esperado. Buscando a los niños desaparecidos de El Salvador (San Salvador, El Salvador: Asociación Pro-Búsqueda y UCA Editores, 2001); Ralph Sprenkels (ed.), Historias para tener presente (San Salvador, El Salvador: Asociación Pro-Búsqueda y UCA Editores, 2002); Ralph Sprenkels, Lives Apart. Family Separation and Alternative Care Arrangements During El Salvador's Civil War (Estocolmo, Suecia: Save the Children, 2003); Margaret Ward, Missing Mila, Finding Family. An International Adoption in the Shadow of the Salvadoran Civil War (Austin, EE. UU.: University of Texas Press, 2011); Elizabeth Barnert, Eric Stover, Gery Ryan y Paul Chung, "Long journey home: Family reunification experiences of the disappeared children of El Salvador", Human Rights Quarterly 37, n. 2 (2015): 492-510, DOI: https://doi.org/10.1353/hrq.2015.0028.

52 Sprenkels, El día más esperado...; Ralph Sprenkels, Caminar con el pueblo: entrevista con Jon Cortina (San Salvador, El Salvador: Ediciones Populares, 2009).

53 Corte Interamericana de Derechos Humanos, Caso de las hermanas Serrano Cruz, Sentencia de 1 de marzo de 2005, disponible en URL: http://goo.gl/cXqzwA.

54 Veáse el sitio web de la Comisión Nacional de Búsqueda, disponible en URL: http://www. cnbelsalvador.org.sv/.

55 La cineasta salvadoreña Marcela Zamora incluyó dichas declaraciones públicas en su docu- 
insistencia de la prensa, el Presidente no quiso aclarar en realidad cuál de las dos existencias negaba: la del archivo o la de la información pertinente. ${ }^{56}$

Tal como se evidencia acá, los esfuerzos hechos por el Archivo de la Policía Nacional en Guatemala y por Pro-Búsqueda en El Salvador lograron insertar en la oficialidad de sus respectivos estados una visión alterna del pasado, aunque ubicada aún en una posición relativamente marginal. En el caso de Guatemala tuvieron asimismo una gran trascendencia en la lucha contra el olvido impuesto los juicios contra perpetradores, que han llevado ya a varias condenas. Esto fue posible porque la amnistía proclamada en Guatemala no tuvo el alcance enorme que sí tuvo la de El Salvador. ${ }^{57}$ El caso contra el ex-dictador Ríos Montt sobre su responsabilidad en el genocidio en contra de la población Ixil se ha convertido en el juicio más sonado de la posguerra guatemalteca. ${ }^{58}$ Este caso también logró una sentencia condenatoria, aunque la Corte Suprema luego la revocó, y un nuevo juicio se sigue posponiendo. ${ }^{59}$

En El Salvador, la derogación, en julio 2016, de su Ley de Amnistía General para la Consolidación de la Paz tiene la posibilidad de abrir nuevos espacios para la lucha contra el olvido. Por lo menos, parecen estar preocupados los militares y también algunos políticos. La alta dirigencia del FMLN y los oficiales veteranos del la Fuerza Armada se han unido en su rechazo a la derogación, que a sus ojos constituye una invitación al revanchismo. ${ }^{60} \mathrm{La}$ comisión política del FMLN encuentra asimismo en la derogatoria de Ley de Amnistía y otras resoluciones simultáneas de la Sala de lo Constitucional de la

mental "Las Aradas: masacre en seis actos". Está disponible en la plataforma digital Vimeo, URL: https://vimeo.com/99660192.

56 Ibid.

57 Mack Chang, "La reconciliación en Guatemala...."

58 Roddy Brett, "Peace Without Social Reconciliation? Understanding the Trial of Generals Ríos Montt and Rodriguez Sánchez in the Wake of Guatemala's Genocide", Journal of Genocide Research, 18, n. 2-3 (2016): 285-303, DOI: http://dx.doi.org/10.1080/14623528.201 6.1186955 .

59 Jo-Marie Burt, "From Heaven to Hell in Ten Days: the Genocide Trial in Guatemala", Journal of Genocide Research, 18, n. 2-3 (2016): 143-169, DOI: http://dx.doi.org/10.1080/146 23528.2016.1186437;

Maira Ixchel Benítez Jiménez, "Guerra y posconflicto en Guatemala: búsqueda de justicia antes y después de los acuerdos de paz", Ciencias Sociales (Colombia) 19 (mayo-agosto 2016): 141-166, DOI: http://dx.doi.org/10.18046/recs.i19.2167. Veáse también el documental Burden of Peace, del director holandés Joey Boink.

60 Veánse por ejemplo: Diario el Mundo, "FMLN ve golpe de Estado si derogan la Ley de Amnistía", 26 de mayo de 2016; América Economía, "Presidente El Salvador critica fallo que declaró inconstitucional polémica ley de amnistía", 16 de julio 2016; El Faro, "Al FMLN se le atraganta la inconstitucionalidad de la Ley de Amnistía", 18 de julio de 2016. 
Corte Suprema una "perversa intencionalidad ... destabilizadora". ${ }^{61}$

De los tres países posbélicos en el istmo, la lucha contra la impunidad y el olvido en Nicaragua presenta un panorama marcadamente divergente. Contrario a los otros dos países, Nicaragua vivió no una, sino dos transiciones políticas profundas: una después del derrocamiento de Somoza en 1979 y otra después de la derrota electoral sandinista, y la entrega del poder a Violeta Chamorro en 1990. En la primera transición, el neófito régimen sandinista aplicó la 'justicia del ganador', enjuiciando a figuras del régimen somocista, que en su mayoría ya no estaban en el país. ${ }^{62}$ La transición de los noventa, en cambio, vino acompañada de una política de 'borrón y cuenta nueva', apoyada por las fuerzas políticas mayoritarias, incluyendo a los sandinistas. ${ }^{63}$ Dicha política se tradujo en la completa ausencia de juicios, comisiones esclarecedoras, depuración y reparación para víctimas. Tal como argumenta Astrid Bothmann, la falta de interés en justicia transicional de parte de las élites políticas nicaragüenses, aunada a la debilidad de las organizaciones de derechos humanos nicaragüenses, y a la falta de insistencia internacional en el tema, ha logrado sostener una política de evasión a lo largo de los años. ${ }^{64}$

Así, la lucha en contra del olvido impuesto se convirtió en una propuesta importante del ámbito de trabajo de la memoria en Guatemala y en El Salvador, mas no en Nicaragua. Las comisiones esclarecedoras en Guatemala y El Salvador no fueron, ni mucho menos, un punto final en la lucha contra el olvido impuesto en estos dos países, tal como fueron concebidos en algunos momentos por oficiales políticos partidarios, sino que más bien se convirtieron en un punto de partida. Si bien, en su origen, muchos activistas guatemaltecos y salvadoreños de derechos humanos estaban vinculados con las organizaciones guerrilleras, la falta de interés de los antiguos dirigentes revolucionarios en la lucha por la justicia generó distanciamientos. Paralelamente, algunas organizaciones de derechos humanos comenzaron a incluir en su agenda la necesidad de esclarecer también casos de abusos de parte de las organizaciones guerrilleras. Esta inclusión de visiones críticas sobre el accionar guerrillero implicaba que en la gestión de la heurística del olvido impuesto se enfatizara cada vez más en el divorcio entre los que hicieron la guerra y los que sufrieron la guerra.

61 Comunicado del Frente Farabundo Martí para la Liberación Nacional, FMLN, 16 de julio de 2016, disponible en URL: http://fmln.org.sv/index.php/comunicados-oficiales/1517-c160716.

62 Astrid Bothmann, Transitional Justice in Nicaragua (1990-2012) (Wiesbaden, Alemania: Springer, 2015).

63 Ibid, 115.

64 Ibid, 157. 
Hasta ahora, a grandes rasgos, en Guatemala y El Salvador el segmento del trabajo de la memoria que se desarrolló bajo la heurística de (la lucha contra) el olvido impuesto se restringió entonces al ámbito de la llamada sociedad civil. Se apoyó fuertemente en grupos organizados de víctimas de la violencia represiva y contó con apoyos importantes de organismos internacionales de defensa de los derechos humanos. Colocó al Estado y a los principales dirigentes y partidos políticos más bien en una posición defensiva. Enfrentó fuerte oposición, no solo de parte de sectores conservadores y reaccionarios vinculados históricamente a posiciones anticomunistas, sino también, aunque en menor medida, de parte de sectores políticos de izquierda temerosos de que el esclarecimiento revelara verdades incómodas sobre el actuar guerrillero. ${ }^{65}$ De esta forma, la memoria de las víctimas de la violencia ha recibido aún limitados, aunque significativos, reconocimientos oficiales y políticos. Los avances recientes en los sistemas judiciales son aún precarios, y han provocado grandes presiones desde la política partidaria y los estamentos conservadores y reaccionarios sobre los jueces y magistrados involucrados. ${ }^{66}$

\section{La heurística del desengaño}

Una segunda categoría en el trabajo de la memoria de la guerra la describe, entre otros, la antropóloga Diane Nelson en sus textos sobre la posguerra guatemalteca ${ }^{67}$ Esta propuesta heurística representa a la guerra como un engaño. Nelson establece esta categoría a partir de su trabajo en comunidades indígenas, demostrando cómo los pobladores se auto-representan como manipulados o engañados, principalmente por el Estado, pero también por los insurgentes, para tomar ciertas decisiones y papeles, que en última instancia solamente resultaron dañinos para los pobladores mismos. Similarmente, tal como Nick Copeland analiza en su artículo "Guatemala nunca va a cambiar", ${ }^{68}$ las comunidades mayas representan a la guerra como un episodio de desencuentro más con

65 Sprenkels, El día más esperado..., 237; Sprenkels, The Price of Peace..., 91.

66 Jemima García-Godos y Luis Raúl Salvadó, "Guatemala: Truth and Memory on Trial", en: Transitional Justice in Latin America: The Uneven Road from Impunity towards accountability, (ed.) Elin Skaar, Jemima Garcia-Godos, Cath Collins (Londres, Inglaterra: Routledge, 2016).

67 Diane Nelson, A Finger in the Wound. Body Politics in Quincentennial Guatemala (Berkeley, EE. UU.: University of California Press, 1999): Diane Nelson, Reckoning: The Ends of War in Guatemala (Durham, Carolina del Norte, EE. UU.: Duke University Press, 2009).

68 Nick Copeland, “'Guatemala Will Never Change': Radical Pessimism and the Politics of Personal Interest in the Western Highlands", Journal of Latin American Studies, 43, n. 3 (agosto 2011): 485-515, DOI: https://doi.org/10.1017/S0022216X11000411. 
el mundo ladino, como una tragedia más en una larga letanía de tragedias, generando una sensación altamente pesimista de continuidades históricas, en las que la violencia bélica tiende a perder su definición precisa en el tiempo, invadiendo simbólicamente todo el espacio temporal. Dickson-Gómez apunta a un fenómeno similar en su trabajo sobre comunidades campesinas salvadoreñas que viven la posguerra como un espacio impregnado por la desconfianza y el desengaño producto de la guerra. ${ }^{69}$

En Nicaragua, el desengaño se alimenta fuertemente de la trayectoria de la revolución sandinista, que a los ojos de muchos nicaragüenses, fue de más a menos con el paso de los años. Por ejemplo, el documental "Palabras mágicas (para romper un encantamiento)", de la cineasta nicaragüense Mercedes Moncada, lleva como eje principal el tema del desengaño. ${ }^{70}$ Hecha desde la perspectiva de una antigua simpatizante sandinista que revisita la historia del movimiento, la película muestra la pérdida de fe en el proyecto y, sobre todo, en su dirigencia. Como consecuencia, tal como lo dice el "voice over', "la muerte dejó de ser heroica y fecunda, es solo muerte y nada más". De similar manera, los trabajos académicos de antropólogos como Irina Carlota Silber y Leigh Binford han documentado el desencanto posrevolucionario en el contexto salvadoreño. Dichos trabajos muestran cómo, alimentado por el distanciamiento con la dirigencia, la precariedad del contexto económico de la posguerra y la pérdida de horizontes utópicos, las antiguas bases campesinas de la guerrilla salvadoreña sufrieron fuertes desilusiones en el contexto de la posguerra. ${ }^{71}$

69 Julia Dickson-Gómez, "The Sound of Barking Dogs: Violence and Terror among Salvadoran Families in the Post-war", Medical Anthropology Quarterly, 16, n. 4 (2002): 415-438, DOI: http://dx.doi.org/10.1525/maq.2002.16.4.415; Julia Dickson-Gómez, "“One Who Doesn't Know War, Doesn't Know Anything': The Problem of Comprehending Suffering in Postwar El Salvador", Anthropology and Humanism, 29, n. 2 (2004): 145-158, DOI: http:// dx.doi.org/10.1525/ahu.2004.29.2.145.

70 Película estrenada en 2012.

71 Irina Carlota Silber, Everyday revolutionaries. Gender, Violence and Disillusionment in Postwar El Salvador (New Brunswick, Canadá: Rutgers University Press, 2011); Leigh Binford, "A Perfect Storm of Neglect and Failure: Postwar Capitalist Restoration in Northern Morazán, El Salvador”, Journal of Peasant Studies, 37, n. 3 (2010): 531-557, DOI: http://dx.doi.org/10.1080/03066150.2010.494375. 
La heurística del desengaño se relaciona asimismo con las duras realidades socio-económicas y la expansión endémica de la violencia 'social' en la Centroamérica de la posguerra. No hay monumentos que proclamen que "la paz es peor que la guerra" -la frase viene de un estudio de la antropóloga estadounidense Ellen Moodie ${ }^{72}$ - pero ideas similares se expresan en otros productos culturales y mnemónicos, por ejemplo, en las artes plásticas o en la literatura centroamericana. El autor nicaragüense William Grisby Vergara habla de Nicaragua como "un país de jóvenes frustrados". ${ }^{73}$ Las novelas del salvadoreño Horacio Castellanos Moya o del guatemalteco Marco Antonio Flores no vinculan el desengaño solamente con el desencanto revolucionario, sino también con la mezquindad y la desesperanza, creando obras literarias impregnadas por lo que Beatriz Cortéz llama "la estética del cinismo". ${ }^{74}$ En estas representaciones, la guerra funge ya no como un motor del avance de la historia, sino como una ilustración más de lo difícil que resulta que Centroamérica cambie para mejorar.

La heurística del desengaño se conecta con lo que podría calificarse como una resaca política, extendida en toda la región latinoamericana a partir de mediados de los años noventa. Tal como lo identificara un ambicioso estudio realizado en 2004 por el Programa de Desarrollo de las Naciones Unidas (PNUD) sobre el estado de la democracia en América Latina, las transiciones democráticas latinoamericanas de los ochenta y noventa no lograron restablecer en la población ni una confianza plena en la democracias, ni mucho menos en los partidos políticos y sus dirigentes. ${ }^{75}$ Una vez agotado el entusiasmo generado por el derrumbe del autoritarismo, se engendró un nuevo escepticismo popular hacia los sectores políticos dominantes, alimentado por la corrupción, la desigualdad y su falta de respuesta a las demandas populares. ${ }^{76} \mathrm{Si}$ bien este escepticismo se pudo atribuir en parte a los efectos negativos de las medidas neoliberales que acompañaron a las transiciones democráticas, y, de esa forma, pudo ser capitalizado en varios países por una nueva izquierda electoral,

72 Ellen Moodie, El Salvador in the Aftermath of Peace. Crime, Uncertainty and Transition to Democracy (Philadelphia, EE. UU.: University of Pennsylvania Press, 2010).

73 Veáse: Foro Nicaragüense de Cultura, "El escritor William Grisby Vergara presentó recientemente su novela", URL: http://foronicaraguensedecultura.org/una-novela-de-la-posguerra-desencanto-y-erotismo/.

74 Beatriz Cortéz, La estética del cinismo: Pasión y el desencanto en la literatura centroamericana de posguerra (Guatemala, Guatemala: F\&G Editores, 2010).

75 Programa de Naciones Unidas para el Desarrollo, La Democracia en América Latina. Hacia una democracia de ciudadanas y ciudadanos (Buenos Aires, Argentina: Alfaguara, 2004).

76 Ibid. 
a los ojos de una parte de la población latinoamericana también esa misma izquierda terminó enredándose en los mismos vicios de los políticos de antaño. ${ }^{77}$

En su forma más cruda, la heurística del desengaño presenta a toda la 'clase política', de izquierda y de derecha, como parasitaria. Utilizando la política como modus vivendi, los políticos extraen riqueza de la sociedad y con ello se agencian unas comodidades que, para las mayorías, son inalcanzables. A la vieja 'clase política' de la 'burguesía de derecha' ahora se habría sumado una nueva 'burguesía de izquierda'. Según esta visión, ambos bandos pelearon las guerras centroamericanas fundamentalmente en función de sus intereses personales y partidarios. Y a la fecha, los herederos políticos de los bandos bélicos siguen prosperando a costa del pueblo. Bajo esta percepción la ideología importa poco, ya que al final la práctica política de acumulación de poder y riqueza es esencialmente la misma.

\section{Tres propuestas heurísticas 'partidarias' o 'oficialistas': la fraternicida, la revolucionaria y la anticomunista}

La heurística del desengaño contrasta obviamente con las lecturas de las guerras centroamericanas que se han venido haciendo desde la oficialidad o desde los sectores políticos partidarios. Como veremos, lo que predomina entre estos sectores son las narrativas que enfatizan las brechas que, en su momento, justificaron la violencia bélica, tanto desde la corriente insurgente como desde la contra-insurgente. A la vez, se dieron algunos tímidos intentos de gestionar lo que podría calificarse como un tipo de memoria 'light' de la guerra. Esto ocurrió sobre todo en los primeros años de la posguerra, y principalmente a nivel del oficialismo estatal. Fueron iniciativas que se ampararon en la bandera de la reconciliación y que, en su mayoría, se desarrollaron paralelamente a los intentos de imposición del olvido descritos anteriormente.

Proponiendo una 'heurística fraternicida', varias iniciativas buscaban entonces representar a las guerras centroamericanas como luchas entre hermanos, y buscaban señalar el fin de las guerras en términos de una síntesis simbólica de un pueblo anteriormente dividido. El Monumento a la Paz en San Salvador, hecho de fusiles descartados y ubicado en una de las principales

77 Alexander Main y Gustavo Codas, "The End of a Progressive Cycle?", NACLA Report on the Americas, 48, n. 4 (2016): 381-384, DOI: http://dx.doi.org/10.1080/10714839.2016.125 8283; veáse también Benedicte Bull, "Social Movements and the 'Pink Tide' Governments in Latin America: Transformation, Inclusion and Rejection", en: Democratization in the Global South: The Importance of Transformative Politics, (ed.) Kristian Stokke y Olle Törnquist (Basingstoke, Inglaterra: Palgrave, 2013). 
vías de entrada a la ciudad, constituye el ejemplo primordial de la memoria de la guerra como fraternicidio en El Salvador. Sin embargo, a pesar de su relevancia para facilitar la convivencia pacífica entre tradicionales enemigos, estas propuestas 'reconciliadoras' de memoria de la guerra perdieron tracción a medida que avanzaba la transición. ${ }^{78}$ Dicho eso, en la actualidad, la memoria fraternicida sigue siendo parte del paisaje memorial en El Salvador. En las ocasiones en las que aún se evoca, sirve para enfatizar la importancia de la reconciliación y disminuir la de la justicia.

En Guatemala, el gobierno también erigió un Monumento a la Paz en 1997. El monumento, ubicado en la principal plaza de la capital, frente al palacio presidencial, consiste en una base de granito con una placa que muestra una paloma y, en la parte superior, una vasija protegida por vidrios, donde está ubicada la llama eterna de la paz. Sin embargo, a los pocos años, el monumento ya mostraba signos de franco deterioro: la llama eterna se había extinguido y la estructura se había llenado de graffiti. ${ }^{79}$ Al igual que en El Salvador, la memoria fraternicida ha tenido una existencia relativamente marginal en la arena nacional de la gestión de la memoria en Guatemala.

En cambio, gradualmente fue en aumento un trabajo de la memoria caracterizado por la reproducción de la bipolaridad ideológica de la guerra, reviviendo el imaginario del enemigo y glorificando a los líderes y los actos de guerra desde cada bando. Claramente, la pugna en el ámbito del trabajo de la memoria entre una heurística revolucionaria y otra anticomunista no comienza con la posguerra, ni con los enfrentamientos armados de las décadas previas. En su trabajo sobre la memoria de la matanza de 1932 en El Salvador, Carlos Gregorio López Bernal describe cómo diversos actores salvadoreños construyeron dos versiones históricas radicalmente distintas de estos sucesos: una construida desde la derecha y otra desde la izquierda. ${ }^{80}$

78 Por ejemplo, si bien en los primeros años de la paz, las conmemoraciones anuales en el Monumento de la Paz en San Salvador reunían a partidarios de todas las fuerzas políticas, en años posteriores, las ausencias a modo de protesta se volvieron comunes.

79 Michael Steinberg y Matthew Taylor, "Public Memory and Political Power in Guatemala's Postconflict Landscape", Geographical Review, 93, 4 (octubre 2003): 459, DOI: http:// dx.doi.org/10.1111/j.1931-0846.2003.tb00042.x.

80 Carlos Gregorio López Bernal, "Lecturas desde la derecha y la izquierda sobre el levantamiento de 1932: implicaciones político-culturales”, en: Erik Ching, Carlos Gregorio López Bernal y Virginia Tilley, Las masas, la matanza y el martinato en El Salvador (San Salvador, El Salvador: UCA Editores, 2007). 
El trabajo de la memoria en Centroamérica: cinco propuestas heurísticas en torno a las guerras en El Salvador, Guatemala y Nicaragua.

Ambas corrientes se insertaron en las pugnas políticas-ideológicas de la Guerra Fría, y se revistieron de gran relevancia en las arenas políticas de Guatemala, El Salvador y Nicaragua en los años sesenta y setenta. A lo largo de los años, las dos corrientes han promovido visiones de la historia bastante consistentes, aunque evidentemente maniqueas. Desde la derecha, la memoria ha girado alrededor del anticomunismo como baluarte y salvador de la patria ante lo que ellos llamaron "el terror rojo". Desde la izquierda, la construcción de la memoria ha girado en torno a la legitimación de la lucha revolucionaria, y especialmente del camino de las armas como única opción. Los hechos históricos trascendentales de los países en cuestión obtuvieron significados radicalmente distintos bajo la óptica de la derecha y la de la izquierda, como fue el caso de la gestión de Jacobo Arbenz en Guatemala, la masacre de 1932 en El Salvador y la guerra de Augusto César Sandino en Nicaragua. ${ }^{81}$

Una parte importante del trabajo de la memoria que se genera en estas dos propuestas heurísticas, que para efectos de simplificación podemos llamar la propuesta revolucionaria y la propuesta anticomunista, se centra en lo que Jansen denomina 'trayectorias reputacionales' de liderazgos históricos. ${ }^{82}$ Desde la derecha, existen una larga tradición de promover como héroes nacionales figuras claves del anticomunismo, como Maximiliano Hernández Martínez, el general que en 1931 se hizo con la presidencia por medio de un golpe de estado y luego ordenó la matanza del 32, o el coronel Domingo Monterrosa Barrios, jefe del Batallón de Reacción Inmediata 'Atlacatl', unidad militar responsable de la matanza de cerca de mil pobladores en el Mozote en

81 Veáse: Roberto García Ferreira, “'Sumida en las tinieblas': Guatemala, 1954”, Revista de Historia de América, 149 (2015): 171-193; María Alejandra Solórzano Castillo, "300: los túneles de la memoria. Acerca de las justificaciones de la violencia en Guatemala", Ístmica (Costa Rica) 15 (2012): 31-37, URL: http://www.revistas.una.ac.cr/index.php/istmica/ article/view/6005; María Dolores Ferrero Blanco, La Nicaragua de los Somoza (19361979) (Huelva, España: Universidad de Huelva, 2010); Stephen Henighan, Sandino's Nation: Ernesto Cardenal and Sergio Ramirez Writing Nicaragua (1940-2012) (Montreal: McGill-Queen's Press, 2014); Jeffrey Gould y Aldo Lauria-Santiago, To Rise in Darkness: Revolution, Repression, and Memory in El Salvador, 1920-1932 (Durham, Carolina del Norte, EE. UU.: Duke University Press, 2009); Héctor Lindo-Fuentes, Erik Ching y Rafael Lara Martínez, Remembering a Massacre in El Salvador: The Insurrection of 1932, Roque Dalton, and the Politics of Historical Memory (Alberquerque, EE. UU.: University of New México Press, 2007); López Bernal "Lecturas desde la derecha..."; Ching, Stories of Civil War ...; Sprenkels, "La memoria militante...".

82 Jansen, "Resurrection and Appropriation...". 
1981, y varias masacres más. ${ }^{83}$ En el caso de Guatemala podemos pensar en el ensalzamiento, de parte de algunos sectores, de Ríos Montt o de Mario Sandoval Alarcón, cerebro de los escuadrones de la muerte. ${ }^{84} \mathrm{La}$ izquierda guatemalteca, en cambio, impulsa a Juan José Arévalo y Jacobo Arbenz, las figuras más importantes de la llamada "primavera guatemalteca" ${ }^{85}$ En Nicaragua, calificaría la pugna en torno a las memorias de Somoza y Sandino, y sus supuestos significados históricos. ${ }^{86}$

En una visita que hice al Museo Militar en San Salvador en 2010, ya con el FMLN en poder ${ }^{87}$ aún me encontré con la representación de Maximiliano Hernández Martínez y Domingo Monterrosa como los dos principales héroes de la nación. ${ }^{88}$ Faltaba entre los héroes del Museo Militar, sin embargo, la persona que podría calificarse como la figura principal del anticomunismo salvadoreño, el mayor Roberto d'Aubuisson. Su ausencia se puede explicar parcialmente por la tensa relación que sostuvo el mayor con la Fuerza Armada luego de su precipitada salida del ejército a raíz del golpe de estado de octubre de 1979 y su detención por la misma Fuerza Armada en mayo de 1980, que derivó en un breve exilio en Guatemala, donde hizo causa común con los más férreos anticomunistas guatemaltecos, incluyendo a Mario Sandoval

83 Veáse: Leigh Binford, The El Mozote Massacre: Human Rights and Global Implications. Revised and Expanded Edition (Tuscon, EE. UU.: University of Arizona Press, 2016); David Morales y Zaira Navas (eds.), Masacres. Trazos de la historia salvadoreña narrados por las víctimas (El Salvador: Centro para la Promoción de los Derechos Humanos "Madeleine Lagadec", 2006).

84 Carlos Figueroa Ibarra, El recurso del miedo: estado y terror en Guatemala (Guatemala, Guatemala: F\&G Editores, 2011).

85 Carlos González Orellana et al., Jacobo Arbenz Guzmán: el soldado del pueblo (Guatemala, Guatemala: Universidad de San Carlos, 2008); Piero Gleijeses, La esperanza destrozada: la revolución guatemalteca y los Estados Unidos (1944-1954) (Guatemala, Guatemala: Editorial de Ciencias Sociales, 2004).

86 Henighan, Sandino's Nation...

87 Mauricio Funes, candidato presidencial del FMLN, asumió el poder el día 1 de junio de 2009.

88 Un año y medio más tarde, en enero de 2012, en el marco de la celebración de los 20 años de los Acuerdos de Paz, el Presidente Funes de El Salvador, responsabilizó a la Fuerza Armada por la masacre de El Mozote y mandó a establecer una comisión que revisara la historia de la Fuerza Armada. También instó a la Fuerza Armada a que dejara de usar nombres de conocidos violadores de los derechos humanos como héroes de la institución. Sin embargo, el informe sobre la historia de la Fuerza Armada se engavetó y, en el momento de escribir este artículo, la tercera brigada de San Miguel sigue nombrándose 'Domingo Monterrosa Barrios'. Veánse: Sprenkels, "La guerra como controversia..."; “Declaración del Presidente Mauricio Funes, del 16 de enero 2012, en El Mozote, en ocasión de XX Aniversario de la firma de los Acuerdos de Paz", disponible en URL: http://goo.gl/KU7SqL. 
El trabajo de la memoria en Centroamérica: cinco propuestas heurísticas en torno a las guerras en El Salvador, Guatemala y Nicaragua.

Alarcón. ${ }^{89}$

Fundador del partido ARENA, d'Aubuisson es, sin embargo, el principal protagonista del trabajo de la memoria realizado desde la derecha partidaria salvadoreña. Cuenta con un mausoleo en el principal cementerio del país y con varios monumentos, incluyendo el enorme monumento a la bandera en Antiguo Cuscatlán, el municipio más pudiente del país, en el cual están inscritas sus frases más celebres, tales como "Patria sí, comunismo no". ${ }^{90}$ Sus seguidores han publicado asimismo memorias y hagiografías en las que d'Aubuisson aparece con cualidades de un semidiós y es lanzado como prócer de la patria. ${ }^{91}$

El trabajo de la memoria desde la derecha salvadoreña, sin embargo, palidece en comparación con el emprendido desde la izquierda partidaria. Las alusiones públicas a figuras revolucionarias se han hecho omnipresentes y cuesta encontrar ya un comandante que no haya publicado sus memorias. El análisis del trabajo de la memoria realizada desde la izquierda revela importantes paralelismos con el de la derecha, incluyendo un fuerte sesgo propagandístico, una incesante búsqueda de héroes y una virtual ausencia de autocrítica. ${ }^{92}$ Los esfuerzos partidarios oficiales ensalzan de manera particular a la figura de Schafik Handal, dirigente del Partido Comunista de El Salvador, una de las cinco facciones que formó el FMLN.${ }^{93}$ Un experimentado político antes de la guerra, Schafik tuvo un papel relativamente modesto en la guerra, pero comenzó a tener más peso en el FMLN a partir de las negociaciones de paz. En la posguerra, lideró las pugnas internas en el FMLN y ayudó a imponer un predominio de la corriente revolucionaria socialista en este partido. ${ }^{94}$ Luego de su muerte en 2006, sus seguidores lo ubicaron en lo más alto del panteón de

89 Geovani Galeas, Mayor Roberto D'Aubuisson. El rostro más allá del mito (San Salvador, El Salvador: La Prensa Gráfica, 2004).

90 Para un análisis de la territorialidad del trabajo de la memoria en El Salvador, veánse: Jorge Juárez, "El despliegue de las memorias: el peso del pasado reciente en El Salvador", en: Historia y debates sobre el conflicto armado salvadoreño y sus secuelas, Jorge Juárez (coord.) (San Salvador, El Salvador: Universidad de El Salvador; Fundación Friedrich Ebert, 2014); Hernández Rivas, Cartografía de la memoria...

91 Sprenkels, "La memoria militante...".

92 Ibid, 270; Ching, Stories of Civil War..., capítulos 4 y 5.

93 Sprenkels, "La memoria militante...".

94 Carlos Gregorio López Bernal, "Schafick Jorge Handal y la 'unidad' del FMLN de postguerra: entre la memoria y la historia. El Salvador (1992-2015)", Diálogos (Brasil) 20, n. 2 (2016): 13-29, URL: http://www.redalyc.org/articulo.oa?id=305549078003. 
la izquierda nacional, eclipsando incluso a figuras históricas como Farabundo Martí, dedicándole un mausoleo y un museo en la capital. ${ }^{95}$ Impresiona el monumento a Schafik en el bulevar Constitución, el mismo bulevar que irónicamente en otro redondel cuenta con un monumento al proceso constituyente de 1983, dirigido por D'Aubuisson. El de Schafik consiste en un obelisco de concreto con una estrella incrustada, y es adornado con una frase de Schafik que es una apología al uso selectivo de la memoria. Dice así: "Si hemos de mirar al pasado, que sea solo para extraer de él firmeza, reafirmación de nuestro carácter revolucionario".

Mientras en El Salvador los partidos ARENA y FMLN dominan la política nacional desde hace más de tres décadas, en Guatemala la sociedad política de la posguerra es mucho más fragmentada. Indicador de ello es que la vida útil de un partido político guatemalteco es muy limitada. La izquierda heredera del proyecto revolucionario insurgente ha sido débil como fuerza electoral. ${ }^{96}$ Muchos partidos en contienda carecen asimismo de una clara agenda política programática. Han evolucionado hacia una especie de 'franquicias políticas ${ }^{97}$ que sufren de 'cartelización'. ${ }^{98}$ Pero, aunque las identidades partidarias y militantes son mucho más débiles, también en Guatemala se encuentra trabajo de la memoria que se ubica en una heurística de la revolución, expresada, por ejemplo, en las memorias publicadas de los comandantes, tales como Pablo Monsanto, César Montes y Gustavo Porras, ${ }^{99} \mathrm{o}$ en el arte conmemorativo visible en la Universidad San Carlos o en las comunidades repobladas con las antiguas bases de la guerrilla. ${ }^{100}$

Mayor presencia en el espacio público la tiene la memoria anticomu-

95 Sprenkels, "La memoria militante...".

96 Ricardo Sáenz de Tejada, Revolucionarios en tiempos de paz: rompimientos y recomposición en las izquierdas de Guatemala y El Salvador (Guatemala, Guatemala: FLACSO, 2007); Michael E. Allison, "The Guatemalan National Revolutionary unit: the long collapse", Democratization, 23, n. 6 (2016): 1042-1058, DOI: http://dx.doi.org/10.1080/135103 47.2016.1159557.

97 Jonatán Lemus, “'Partidos franquicia': La distorsión del modelo de organización de la Ley Electoral y de Partidos Políticos", en: ASIES, Partidos Políticos Guatemaltecos. Cobertura territorial y organización interna (Guatemala, Guatemala: ASIES, 2013).

98 Eduardo Fernández Luiña y Pedro Trujillo Álvarez, "Partidos políticos y competición electoral. Cuando la Ciencia Política confronta el Derecho", Revista de Investigaciones Politicas y Sociológicas (España) 14, n. 1 (2015): 129-146, URL: http://www.usc.es/revistas/ index.php/rips/article/view/2273.

99 Pablo Monsanto, Somos los jóvenes rebeldes. Guatemala insurgente (Guatemala, Guatemala: F\&G Editores, 2013); Gustavo Porras, Las huellas de Guatemala (Guatemala, Guatemala: F\&G Editores, 2009); Julio César Macías Mayora, La guerrilla fue mi camino. Epitafio para César Montes (Guatemala, Guatemala: Editorial Piedra Santa, 1997).

100 Steinberg y Taylor, "Public Memory and Political". 
El trabajo de la memoria en Centroamérica: cinco propuestas heurísticas en torno a las guerras en El Salvador, Guatemala y Nicaragua.

nista que, aunque no tiene un referente partidario-histórico tan claro como lo tiene con ARENA en El Salvador, encuentra su incidencia en el espacio público, por ejemplo, por medio de un batallón de columnistas de prensa. Figuras como Óscar Platero Trabanino, un veterano oficial del ejército guatemalteco, han lanzado libros que no solamente glorifican el actuar del ejército durante la pasada guerra, sino que alertan sobre una supuesta continuidad de las "intentonas" comunistas por derrocar el ejército y el orden político guatemalteco. ${ }^{101}$ Esta supuesta conspiración comunista ya no es encabezada por la guerrilla, sino por ONG's dependientes del apoyo de la cooperación internacional, supuesto centro neurálgico encubierto de la izquierda mundial. ${ }^{102}$

En Guatemala, la campaña anticomunista contemporánea es conducida principalmente por los medios de comunicación y por organizaciones tales como la Fundación contra el Terrorismo, dirigida por Ricardo Méndez Ruiz. Esta organización funde características de una ONG de incidencia política con las de los escuadrones de la muerte de antaño. La Fundación contra el Terrorismo concibe a la sociedad guatemalteca, y al mismo Estado guatemalteco, como entidades infiltradas por marxistas. Los infiltrados son personas nacionales o extranjeras, de extrema izquierda que supuestamente desean continuar la guerra por otros medios. Apoyados por la comunidad internacional, buscarían, con manipulación política y desestabilización, lo que no pudieron lograr por las armas insurgentes. ${ }^{103}$ La Fundación entonces dice dedicarse a la defensa de verdaderos patriotas como Ríos Montt, y no duda, al viejo estilo escuadronero, en intimidar y amenazar con nombre y apellido a supuestos enemigos de la patria en el proceso. ${ }^{104}$

La heurística revolucionaria y la anticomunista también juegan un papel importante en la gestión de la memoria en Nicaragua. Y también en este país se entrelazan con las trayectorias reputacionales de las figuras históricas claves. ${ }^{105}$ Verónica Reuda señala la existencia, a partir ya de los años ochenta,

101 Óscar Platero Trabanino, ¡Las batallas por Guatemala!: crónica investigativa sobre hechos importantes antes, durante y después del enfrentamiento armado interno (Guatemala, Guatemala: Editorial Óscar de León Palacios, 2013); Óscar Platero Trabanino, La farsa del genocidio en Guatemala (Guatemala, Guatemala: Editorial Óscar de León Palacios, 2015).

102 Platero Trabanino, La farsa del genocidio...

103 Para conocer más sobre el pensamiento y los postulados de la Fundación Contra el Terrorismo de Guatemala, veáse el blog que mantiene la Fundación en URL: http://fundacioncontraelterrorismo2013.blogspot.nl/.

104 Carolina Gamazo, "Fundación contra el Terrorismo. El club de la balanza y la daga", Plaza Pública, 25 de junio de 2013, URL: https://www.plazapublica.com.gt/content/elclub-de-la-balanza-y-la-daga.

105 Verónica Rueda, "Testimonios, confesiones y memorias del sandinismo", Cuadernos Ame- 
de dos corrientes de publicaciones testimoniales: prosandinistas y antisandinistas. ${ }^{106} \mathrm{~A}$ la fecha, la derecha y la izquierda partidaria nicaragüenses ofrecen interpretaciones marcadamente distintas tanto de la gesta de Sandino como de la Revolución Sandinista. Sin embargo, contrario a lo sucedido con las figuras de derecha en El Salvador y Guatemala, el desgaste de Somoza dejó a la derecha nicaragüense en busca de claros referentes históricos. Y para la izquierda las contradicciones surgen a la hora de identificar héroes más allá de la figura de Sandino. ${ }^{107}$

Por ejemplo, Mónica Baltodano, la excomandante del Frente Sandinista para la Liberación Nacional (FSLN), en sus tres tomos de Memorias de la lucha sandinista ${ }^{108}$ afirma que su propósito es rescatar la historia del enfrentamiento contra la dictadura somocista de "las versiones interesadas y falsificadas" que están apareciendo. ${ }^{109}$ Se refiere a intentos de algunos dirigentes sandinistas, entre ellos Daniel Ortega, de atribuirse un papel más heroico en la lucha del cual en realidad tuvieron. De la misma forma, la memoria de la revolución debe separarse, de alguna manera, de los resultados que tuvo, tal como lo expresa la también ex comandante Dora María Téllez, que insiste en que la Revolución Sandinista valió la pena a pesar de que su resultado fue la "reencarnación del somocismo, ... los pactos entre caudillos, la repartición de prebendas y privilegios, el clientelismo político, la corrupción y la impunidad". ${ }^{110}$ Así, mientras Téllez y Baltodano consideran que el Frente Sandinista de antes tiene poco que ver con el partido político que hoy dirigen Daniel Ortega y su esposa Rosario Murillo, estos últimos no escatiman esfuerzos para enfatizar las continuidades históricas, calificando el período actual como "la segunda etapa de la revolución", una revolución que además habría tenido en

ricanos (México) 1, n. 127 (2009): 145-162; Gema Palazón, Memoria y escrituras de Nicaragua: Cultura y discurso testimonial en la Revolución Sandinista (Paris, Francia: Editions Publibook, 2010); Henighan, Sandino's Nation...

106 Rueda, “Testimonios, confesiones y memorias...”, 154.

107 Andrés Pérez-Baltodano, Postsandinismo: Crónica de un diálogo intergeneracional e interpretación del pensamiento político de la Generación XXI (Managua, Nicaragua: Instituto de Historia de Nicaragua y Centroamérica de la Universidad Centroamericana [IHNCA-UCA], 2013).

108 Mónica Baltodano, Memorias de la lucha sandinista, 3 volúmenes (Managua, Nicaragua: Instituto de Historia de Nicaragua y de Centroamérica, 2010).

109 La Prensa, "El somocismo tenía respaldo popular", 12 de febrero 2012, URL: http://www. laprensa.com.ni/2012/02/12/nacionales/90410-el-somocismo-tenia-respaldo-popular.

110 Andrés Pérez-Baltodano, Postsandinismo... 
El trabajo de la memoria en Centroamérica: cinco propuestas heurísticas en torno a las guerras en El Salvador, Guatemala y Nicaragua.

\section{Daniel Ortega su principal guía. ${ }^{111}$}

Las disputas de la memoria de la guerra en Nicaragua se desarrollan más en torno al significado de la revolución y mucho menos en torno a las víctimas que dejó el conflicto armado. ${ }^{12}$ Como ya lo vimos anteriormente, en comparación con El Salvador y Guatemala, los temas de la verdad y de la justicia transicional se encuentran bastante eclipsados en el entorno político nicaragüense. Tal como me lo dijo un periodista que trabaja desde hace dos décadas en Managua, a la fecha los abusos históricos tales como los crímenes de Somoza o las operaciones sandinistas en contra de asentamientos misquitos aparecen fugazmente en el espacio público, solo en los momentos en que resultan útiles para increpar al rival político. ${ }^{113}$

\section{Las cinco propuestas heurísticas y su dinámica política}

La principal diferencia entre las cinco propuestas heurísticas consiste en que cada propuesta explica la guerra y sus resultados a partir de otra brecha. Los más parecidos en este sentido son la heurística del olvido impuesto y la del desengaño. La del olvido impuesto enfatiza la brecha entre los que hicieron la guerra -las partes bélicas, principalmente el Estado-y los que sufrieron la guerra -las víctimas-. Similarmente, la heurística del desengaño propone ver a dirigentes de ambos bandos -revolucionarios y contra-revolucionarioscomo responsables de la guerra e identifica al pueblo, al ciudadano común o al ingenuo, como el que paga la factura. La diferencia entre ambas propuestas heurísticas es que la primera históricamente enfatiza y prioriza la brecha entre el Estado y las víctimas, mientras la segunda enfatiza la brecha entre la clase política y el pueblo. A cambio, la heurística fraternicida representa a las partes bélicas como hermanos de un mismo pueblo, cuya reconciliación asimismo se traduce en la reconciliación de todo el pueblo. La heurística revolucionaria a su vez culpa a la represión salvaje de las dictaduras militares como responsable de fomentar una brecha tal entre régimen y pueblo que no dejó alternativa más que la lucha armada. La anticomunista, al contrario, culpa al radicalismo

111 Andrés Pérez-Baltodano, "Nicaragua: Democracia electoral sin consenso social", Revista de Ciencia Política (Chile) 32, n. 1 (2012): 211-228, disponible en URL: http://www. scielo.cl/pdf/revcipol/v32n1/art11.pdf; Veáse también: La Prensa, "Daniel Ortega busca ahora 26 años en el poder", 7 de noviembre de 2016, URL: http://www.laprensa.com. ni/2016/11/07/politica/2127875-daniel-ortega-26-anos-poder.

112 Lorraine Bayard de Volo, Mothers of Heroes and Martyrs: Gender Identity Politics in Nicaragua (1979-1999) (Baltimore, Maryland, EE. UU.: John Hopkins University Press, 2001).

113 Entrevista del autor con Iván Castro, corresponsal de prensa afincado en Managua, 23 de agosto de 2016. 
y la perversidad de las organizaciones guerrilleras de haber provocado la guerra y las responsabiliza de sus costos humanos.

Si bien algunas interpretaciones alternativas o más refinadas y matizadas sobre las dinámicas de las pasadas guerras existen, por ejemplo en ámbitos académicos ${ }^{114}$, estas suelen tener poca presencia en la gestión pública del trabajo de la memoria. En cambio, las cinco propuestas heurísticas identificadas, juntas, dominan el ámbito de trabajo de la memoria en torno a las pasadas guerras en los tres países, aunque en cada país con configuraciones distintas. Esta variación se relaciona principalmente con las trayectorias históricas de los sectores vinculados con determinada propuesta heurística en cada país. La lucha contra el olvido impuesto tiene sus mayores nodos de acción en los organismos de derechos humanos. El anticomunismo los tiene en la antigua derecha política y sus herederos, incluyendo militares retirados en Guatemala y El Salvador. La categoría de la revolución aparece principalmente en la izquierda partidaria -con mayor fuerza en El Salvador y Nicaragua-, y en grupos gremiales de izquierda -con mayor fuerza en Guatemala-. ${ }^{115}$ La heurística fraternicida se apega más a la diplomacia y la oficialidad. A pesar de que pocos tal vez crean de manera genuina en la guerra como un fraternicidio, resulta una narrativa útil cuando las circunstancias políticas demandan apelar a la reconciliación. ${ }^{116} \mathrm{El}$ desengaño, aunque capaz de permear muchos ámbitos, tiene una resonancia particular entre artistas, intelectuales y jóvenes centroamericanos.

Así, cada propuesta heurística encuentra su anclaje principal en un sector político distinto, y se asocia también con una agenda política contemporánea distinta. La lucha contra el olvido impuesto, a pesar de sus orígenes de izquierda, se ha ido posicionando a grandes rasgos como una agenda externa a la política partidaria. Las heurísticas revolucionarias y anticomunistas se asocian aún hoy en día con proyectos partidarios de derecha y de izquierda.

114 El mejor ejemplo probablemente sea el trabajo de Edelberto Torres-Rivas. Veáse, por ejemplo, Edelberto Torres-Rivas, Revoluciones sin cambios revolucionarios: ensayos sobre la crisis en Centroamérica (Guatemala, Guatemala: F\&G Editores, 2011).

115 Mathijs van Leeuwen, "To Conform or to Confront? CSOs and Agrarian Conflict in PostConflict Guatemala", Journal of Latin American Studies, 42, 1 (2010): 91119, DOI: https:// doi.org/10.1017/S0022216X10000064.

116 Por ejemplo, y tal como sugeririera Carlos Gregorio López Bernal en el coloquio, "Las múltiples huellas del recuerdo", en El Salvador, la derogación en 2016 de la Ley de Amnistía ha hecho más atractivas las visiones reconciliatorias sobre la guerra para dirigentes políticos de derecha y izquierda. 
La heurística fraternicida apela al imaginario de la vigencia de la transición democrática. Y aunque la heurística del desengaño no ofrece mucha esperanza, se asocia en general con la necesidad de una renovación total del sistema político.

Las cinco propuestas heurísticas coexisten y, en ocasiones, compiten por el espacio público de la posguerra centroamericana. ${ }^{117}$ El reconocimiento de estas cinco propuestas heurísticas nos ayuda a entender no solo el funcionamiento de la arena política contemporánea, sino también las hondas raíces históricas que han nutrido esta arena política a lo largo de la posguerra. Sin embargo, pienso que no tiene sentido estudiar y utilizar a las cinco propuestas heurísticas de manera rígida. La gestión de la memoria se encuentra en un continuo movimiento y cada una de las propuestas presenta dentro de sí aún un espectro considerable de variación en las narrativas ofrecidas.

Por ejemplo, aunque las narrativas de los antiguos comandantes guerrilleros que han publicado sus memorias invariablemente justifican la legitimidad y la urgencia de empunar las armas para liberar o defender al pueblo, existen entre ellos algunos que apelan a la heurística fraternicida cuando se posicionan en torno al tema de la justicia transicional. Un ejemplo es la oposición del guatemalteco Gustavo Porras, exdirigente de la organización Ejército Guerrillero del los Pobres (EGP), al juicio por genocidio en contra de Ríos Montt. ${ }^{118}$ De similar forma, la reciente derogación de la Ley de Amnistía en El Salvador ha empujado a dirigentes políticos a desempolvar la retórica de la guerra fraternicida.

Otro ejemplo lo ofrece el historiador Erik Ching en su análisis de las historias de vida publicadas por protagonistas de la guerra en El Salvador. Ching propone que las narrativas desde la derecha anticomunista deben subdividirse en dos interpretaciones distintas: la de los oficiales militares y la de las élites civiles. Aunque ambas narrativas se inscriben en una tradición anticomunista, los oficiales militares culpan, además, también a las élites civiles, alegando que su intransigencia a las reformas alimentó la guerra, mientras las élites civiles consideran que fueron los intentos reformistas empujados por los militares los que echaron fuego al conflicto. ${ }^{119}$ En El Salvador, tal como lo apunta la historiografía, fue la alianza entre oligarquía y militares que, junto con los EE.UU., sostuvo la guerra. Ya en la posguerra, en su trabajo de la memoria, los integrantes de esta alianza enfatizan sus diferencias, e incluso

117 Juárez, "El despliegue de las memorias..."; Sprenkels, "La memoria militante...".

118 Carlos Figueroa Ibarra, "Gustavo Porras y el genocidio", Narrativa y Ensayo, 3 de mayo de 2013, URL: http://www.narrativayensayoguatemaltecos.com/ensayos/ensayos-sociales/gustavo-porras-y-el-genocidio-de-carlos-figueroa-ibarra/.

119 Ching, Stories of Civil War..., capítulos 2 y 3. 
ignoran o critican el rol jugado por el otro. De similar manera, Ching revela las importantes diferencias entre las memorias publicadas de los comandantes de la guerrilla y las de los ex-combatientes o colaboradores. Ambos grupos hablan de los heroísmos de la revolución, pero mientras los comandantes enfatizan que la guerra destruyó la dictadura y transformó el país, los que tuvieron un rango bajo en la guerrilla enfatizan que sus sacrificios no obtuvieron mucha recompensa, ya que las reformas logradas no fueron profundas, ni se materializaron muchos de los beneficios que esperaban. ${ }^{120}$

Cada propuesta heurística puede englobar entonces diferentes subcorrientes, con distintas lecturas y posiciones. También es importante destacar que no toda figura histórica se puede asignar clara o exclusivamente como abanderado de una de las categorías. Un ejemplo es el caso de Monseñor Romero. Conocido como 'la voz de los sin voz', Romero es un símbolo de la lucha en contra del olvido impuesto en El Salvador, e incluso más allá. Pero la figura de Monseñor Romero es disputada. No solo el movimiento de derechos humanos ocupa la figura de Monseñor Romero, también lo hace el partido político FMLN, que tiende a enfatizar sus mensajes a favor de las transformaciones estructurales y en contra del régimen, obviando o minimizando las críticas que Romero tuvo en su momento hacia las organizaciones político-militares y la lucha armada. ${ }^{121}$

El trabajo de la memoria en torno a Monseñor Romero también es un buen ejemplo de cómo las trayectorias reputacionales de figuras históricamente relacionadas tienden a afectarse mutuamente. Mientras la reputación de Romero ha cobrado nuevos brillos a partir de su beatificación, ${ }^{122}$ la reputación de su verdugo, el líder escuadronero y fundador de ARENA, Roberto d'Aubuisson, ha estado deteriorándose. En 2014, cuando sus partidarios, aprovechando que la alcaldía estaba en manos de ARENA, cambiaron el nombre de una calle de la capital por el de D'Aubuisson, se generó un fuerte revuelo público, y a los pocos meses, ya con el FMLN en el poder, la decisión se revirtió. ${ }^{123}$ La reputación de D'Aubuisson parece haber comenzado a dividir a ARENA, ya que han aparecido en años recientes más voces al interior de ARENA que proponen obviar la figura de D'Aubuisson y abandonar el anticomunismo virulento.

\section{Conclusiones}

120 Ibid, capítulos 4-6.

121 James Brockman, La palabra queda. Vida de Monseñor Óscar A. Romero (San Salvador, El Salvador: UCA Editores, 1985).

122 Monseñor Romero se convirtió en beato de la Iglesia Católica el 23 de mayo de 2015.

123 El Faro, "Calle Roberto d'Aubuisson", 1 de mayo de 2015, URL: https://elfaro.net/ es/201504/noticias/16927/Primer-concejo-plural-capitalino-se-estrena-borrando-el-nombre-calle-Roberto-d'Aubuisson.htm. 
En este artículo he presentado una breve revisión de las tendencias principales en el trabajo de la memoria vinculado con las pasadas guerras en Nicaragua, Guatemala y El Salvador. Mi exploración de este fenómeno en los tres países identifica claras similitudes en la gestión del trabajo de la memoria de acuerdo a determinadas propuestas heurísticas. Sin pretender ser exhaustivo, considero que la mayor parte del trabajo de la memoria sobre la guerras centroamericanas se vincula con alguna de las cinco propuestas heurísticas identificadas en este artículo: el olvido impuesto, la guerra fraternicida, la revolución, el anticomunismo, y el desengaño.

Aunque cada propuesta encuentra su anclaje en determinados sectores históricos, sectores que asimismo funcionan como comunidades mnemónicas, la relación entre propuesta heurística y actor social no es estática ni inmutable. $\mathrm{Al}$ interior de diversas comunidades mnemónicas pueden identificarse además subcorrientes que, sin salirse de su marco heurístico global, disputan el valor relativo de las contribuciones históricas de determinados (sub)grupos o individuos a la causa común.

Cada país, asimismo, ofrece una configuración distinta del poder relativo de los sectores históricos y también de la incidencia relativa de la propuesta heurística asociada con este sector. En términos relativos y comparativos, en Nicaragua abunda el trabajo desde la heurística revolucionaria empujada desde la oficialidad, y escasea el trabajo que se podría enmarcar en la heurística del olvido impuesto. En El Salvador, en cambio, las propuestas heurísticas revolucionarias y anticomunistas cuentan con una fuerte presencia pública, empujada en gran parte desde la política partidaria. En Guatemala, la principal pugna parece darse entre la propuesta anticomunista y la propuesta contra el olvido impuesto. En los tres países, la heurística del desengaño constituye una corriente relativamente soslayada, pero significativa en la vida pública.

En la actualidad centroamericana, las memorias de la guerra se usan y se abusan para agendas políticas y personales de varios colores. No hay consensos ni sobre lo que causó las guerras ni sobre sus hechos principales, ni tampoco sobre las supuestas lecciones históricas que generaron para las sociedades en cuestión. Desde la academia, no solamente estudiamos diferentes propuestas interpretativas sobre el pasado, sino también, inevitablemente quizás, las empujamos.

Desde mi perspectiva, el trabajo de la memoria está íntimamente relacionado con la acumulación de capital cultural y simbólico, y por ende con proyectos de poder, tanto a nivel individual como a nivel colectivo. El trabajo de la memoria otorga significado y valor a estos proyectos, anclándolos en una supuesta acumulación histórica. ${ }^{124}$ Pero esto no quiere decir que se trate de entes fijos. Son más bien proyectos políticos emergentes, que necesitan

124 Ankersmit, Political Representation. 
renovarse continuamente y que, sin embargo, dependen de sus nexos con el pasado para legitimarse. Por medio del trabajo de la memoria, las pasadas guerras mantienen una enorme vigencia política en Centroamérica, principalmente -mas no exclusivamente- para alentar animosidades. Lejos aún de cristalizarse una interpretación histórica sobre estas guerras que amplios y variados sectores acepten como justa y legítima, lo que predomina es la polémica y la fragmentación. 